\title{
Formulation and Pharmacokinetic Evaluation of Microcapsules Containing Pravastatin Sodium Using Rats
}

\author{
Venkatesh Dinnekere Puttegowda, ${ }^{1}$ Roopa Karki, ${ }^{1}$ Divakar Goli, \\ Sajal kumar Jha, ${ }^{2}$ and Manjunatha Panduranga Mudagal ${ }^{1}$ \\ ${ }^{1}$ Department of Pharmaceutics \& Pharmacology, Acharya and B. M. Reddy College of Pharmacy, Soldevanahalli, \\ Bengaluru 560107, India \\ ${ }^{2}$ Department of Pharmaceutics, School of Pharmacy, Guru Nanak Institutions Technical Campus, Ibrahimpatnam, \\ Telangana, India
}

Correspondence should be addressed to Venkatesh Dinnekere Puttegowda; venkateshdp27@gmail.com

Received 11 December 2015; Revised 3 May 2016; Accepted 8 June 2016

Academic Editor: Roberta Fruttero

Copyright (C) 2016 Venkatesh Dinnekere Puttegowda et al. This is an open access article distributed under the Creative Commons Attribution License, which permits unrestricted use, distribution, and reproduction in any medium, provided the original work is properly cited.

\begin{abstract}
Pravastatin Sodium has a cholesterol lowering agent. It has shorter half-life and undergoes first-pass metabolism. Frequent dose is required in case of conventional dosage form. The purpose of the study is to formulate and evaluate microcapsules containing Pravastatin Sodium by complex with cholestyramine resins coated with Eudragit RLPO and Eudragit RSPO polymers for achieving control release. Complexation of drug on resin was carried out by batch method. Microencapsulation was carried out by nonaqueous solvent evaporation method. Pharmacokinetic studies were done by using rats. The intermediate stability studies were carried out on the most satisfactory formulations. FTIR, X-ray diffraction, and DSC spectra of drug, drug-resinates, and polymers revealed no chemical interaction. The \% DEE and \% yield were observed for formulations of f1 to f7 that were varied from $97.1 \pm 0.8$ to $98.9 \pm$ $0.5 \%$ and $95.0 \pm 3.25$ to $98.8 \pm 7.1 \%$, respectively. Most satisfactory formulation, f6, showed drug release up to $72.6 \%$. No changes in \% DEE and \% CDR were observed after stability studies. Microcapsules of $\mathrm{f} 6$ formulation achieved best performance regarding in vitro drug release and from pharmacokinetic evaluation mean residence time was found to be $6.3 \mathrm{~h}$, thus indicated, Pravastatin Sodium microcapsules were released and absorbed slowly over a prolonged period of time.
\end{abstract}

\section{Introduction}

Pravastatin Sodium is a class of lipid regulating drug, the statins which reduce cholesterol biosynthesis. This agent is competitive inhibitor of HMG CoA reductase. It is an odourfree, white to faded white, fine or crystalline powder. It is a moderately polar, hydrophilic compound. It is, to some extent, rapidly absorbed from the gastrointestinal tract and undertakes extensive first pass metabolism in the liver. The absolute bioavailability of Pravastatin Sodium is $17 \%$. About $50 \%$ of the circulate drug is bound to plasma proteins. Plasma elimination half-life is 1.5 to $2 \mathrm{~h}$. About $70 \%$ of oral dose is excreted in the feces and about $20 \%$ is excreted in the urine [1].
The more established bile acid sequestrants such as cholestyramine and colestipol are among the old hypolipidemic agents, and they are most likely the safest, as they are not absorbed from the intestine. Statins are not as useful as monotherapy; the resins are more frequently used as second agents, if the statin therapy does not lower LDL-C levels sufficiently. When used with cholestyramine and colestipol it is generally prescribed with submaximal doses [2]. The cholestyramine resins are highly positive charged and bind negatively charged bile acids; because of their bulky size, the resins were not absorbed and the bound bile acids are excreted in the feces. In the synthesis caused by upregulation of HMG CoA reductase enzyme activity by a statin considerably increases the effectiveness of the resins [3]. Controlled 
or sustained release property can also be imparted to oral dosage formulation through the development of resin drug complexes (drug-resinates). The drug is released from resin in vivo as the drug-resinates reach equilibrium with the more electrolyte concentration found in the gastrointestinal tract [4]. Resins bind bile acids in the intestine, in this manner interrupting the enterohepatic circulation of the bile acids, and increase the conversion of cholesterol into bile acid in the liver [5].

Ion exchange resins have been used widely in the pharmaceutical industry as drug delivery system. The drug release rate of ion exchange resins can be modified depending on functional group, ion exchange capacity, degree of crosslink, and particle size. Ion exchange resins have fixed ionic functional groups which can provide binding of ionic drugs. Release of the bound drug requires exchange with counter ions such as hydrogen or sodium, which are available in the gastrointestinal tract. The overall drug release kinetics of polymer coated ion exchange resins is mainly dependent upon the drug and counter ion, diffusion confrontation in the coating film and boundary layer (film) surrounding the particles, surrounding medium, liquid diffusion, and drug dissolution [6]. Controlled or sustained release properties can also be impaired to oral dosage formulations through the formation of drug-resinate complex. The drug is released from the resin in vivo as the drug-resinates reach equilibrium with the high electrolyte concentrations typically found in the gastrointestinal tract [5].

When used as an active ingredient, cholestyramine resins are a strong pharmacological bile salt-binding agent that binds bile acid; this leads to replenishment of the bile acids through increasing the catabolism of serum cholesterol resulting in lowered serum cholesterol levels. Bile acids are the end products of cholesterol metabolism. They are synthesized in liver and secrete bile into the intestine, where they aid in the absorption of fat soluble vitamins and dietary fat. Subsequently bile acids come again to the liver to complete their enterohepatic circulation. Resins bind bile acids in the intestine, thereby interrupting the enterohepatic circulation of the bile acids and increasing the renovation of cholesterol into bile acids in the liver [7]. Positively charged anion resins bind negatively charged bile acids, about $95 \%$ of which are normally reabsorbed. Drug release from the resins depends on two factors, the ionic environment, that is, $\mathrm{pH}$ and electrolyte concentration within the gastrointestinal tract, and the properties of the resin [7].

The cholestyramine resin is an insoluble, strongly basic anion exchange resin in the chloride form supplied as dry fine powder. Cholestyramine resins Tulsion 412 was used as a drug carrier for anionic drug Pravastatin Sodium. Ion exchange resins alone without any barrier cannot achieve satisfactory controlled release. Thus resin complexes were coated with polymers for achieving controlled release in the small intestine. Microencapsulation is an effective method to wrap liquid or solid materials which are surrounded by coating with polymeric membrane. The purpose of the study is to formulate microcapsules by complexing Pravastatin Sodium drug with anionic exchange resins and further coat with Eudragit RLPO and Eudragit RSPO polymers for achieving controlled release in the small intestine.

\section{Materials and Methods}

2.1. Materials. Pravastatin Sodium gift sample was collected from Biocon India Ltd, Bengaluru. Tulsion 412 resins collected were gift from Thermax ion exchange Mumbai, India. Eudragit RSPO and Eudragit RLPO polymers gift samples were collected from Evonik's laboratory Mumbai; Span 80 was collected from Karnataka fine chemicals Bengaluru and all other chemicals and solvents used were of analytical grade.

2.2. Drug Polymer Compatibility Studies. Drug polymer interaction studies were carried out by using FTIR, DSC, and $\mathrm{X}$-ray diffraction studies. FTIR spectroscopy is a powerful tool for identifying types of chemical bonds and functional groups and checks the integrity of drug in the formulation. In the present study, a pinch of pure drug was placed in the spectrophotometer and the spectrum was recorded. The characteristic peaks of the pure drug and drug peaks from the formulations were identified. It was performed by FTIR over frequency range $4000-400 \mathrm{~cm}^{-1}$ using Bruker Tensor 27 Germany.

$\mathrm{XRD}$ is required in drug development to assess the state, that is, amorphous or crystalline nature, of the drug and degree of crystallinity of particular substances. Pravastatin Sodium, resins, and drug resin complex were analysed by $\mathrm{X}$ ray powder diffraction. All the samples were run at $(2 \theta) \mathrm{min}^{-1}$ from $10^{\circ}$ to $60^{\circ}(2 \theta)$. The XRD patterns of drug, resins, and drug-resinates were recorded and compared.

Thermal analytical methods used in the characterization of polymorphs, purity and compatibility studies of the sample. Differential scanning calorimeter was used to study thermal transitions of a drug, resins, and drug resin complex. In DSC, thermogram was obtained at a heating rate $10^{\circ} \mathrm{C} / \mathrm{min}$, over a temperature range $35-500^{\circ} \mathrm{C}$. The samples were hermetically sealed in an aluminium crucible. Nitrogen gases were purged at a rate of $10 \mathrm{~mL} / \mathrm{min}$, for maintaining inert atmosphere. The instrument was calibrated for temperature and heat flow using indium and zinc standards, respectively.

2.3. Preparation of Drug-Resinates. Preparation of drugresinates was tried by batch method [5]. Accurately weighed drug and cholestyramine resins were in 1:4 ratios. Then slurry of resin was made in $100 \mathrm{~mL}$ distilled water and stirred half an hour at $500 \mathrm{rpm}$, to allow the polymer structure to swell uniformly. Drug solution in distilled water was slowly added to resin slurry under mixing condition, neutral $\mathrm{pH} 7$ was maintained because at neutral $\mathrm{pH}$ maximum drug load was achieved. The mixture was stirred for $5 \mathrm{~h}$ continuously on magnetic stirrer. Drug loading of Pravastatin Sodium was determined spectrophotometrically at $238.5 \mathrm{~nm}$.

2.4. Determination of Amount of Uncomplexed Drug by UV. The mixture was kept aside to allow the particles to sediment and then filtered. From the filtrate $1 \mathrm{~mL}$ was transferred into $10 \mathrm{~mL}$ volumetric flask; after suitable dilution, drug was 
TABLE 1: Formulation chart.

\begin{tabular}{|c|c|c|c|c|c|c|c|}
\hline $\begin{array}{l}\text { Formulation } \\
\text { code }\end{array}$ & $\begin{array}{l}\text { Drug: resin } \\
\quad \text { ratio }\end{array}$ & $\begin{array}{c}\text { Quantity } \\
\text { of drug } \\
\text { resinates }\end{array}$ & $\begin{array}{c}\text { Eudragit } \\
\text { RSPO (\% } \\
\text { w/w) }\end{array}$ & $\begin{array}{l}\text { Formulation } \\
\text { code }\end{array}$ & $\begin{array}{l}\text { Drug : resin } \\
\quad \text { ratio }\end{array}$ & $\begin{array}{c}\text { Quantity of } \\
\text { drug- } \\
\text { resinates }\end{array}$ & $\begin{array}{l}\text { Eudragit RLPO } \\
(\% \mathrm{w} / \mathrm{w})\end{array}$ \\
\hline f1 & $1: 4$ & $1 \mathrm{~g}$ & - & - & - & - & - \\
\hline $\mathrm{f} 2$ & $1: 4$ & $1 \mathrm{~g}$ & $10 \%$ & f5 & $1: 4$ & $1 \mathrm{~g}$ & $10 \%$ \\
\hline f3 & $1: 4$ & $1 \mathrm{~g}$ & $20 \%$ & f6 & $1: 4$ & $1 \mathrm{~g}$ & $20 \%$ \\
\hline $\mathrm{f} 4$ & $1: 4$ & $1 \mathrm{~g}$ & $30 \%$ & f7 & $1: 4$ & $1 \mathrm{~g}$ & $30 \%$ \\
\hline
\end{tabular}

determined spectrophotometrically at $238.5 \mathrm{~nm}$. The amount of drug loading in percentage was calculated [6].

2.5. Preparation of Microcapsules. Preparations of microcapsules were done as per formulation chart given in Table 1. Microcapsules were prepared by using solvent evaporation technique [8]. A homogenous polymer solution was made in $20 \mathrm{~mL}$ acetone in a beaker. Drug-resinates were dispersed uniformly into $70 \mathrm{~mL}$ liquid paraffin containing one drop of Span 80 in another beaker. It was stirred by using mechanical stirrer at speed of $500 \mathrm{rpm}$. Polymer solution was injected slowly using 20-gauge syringe under stirred condition continuously for 3 to $4 \mathrm{~h}$ until acetone was evaporated. The microcapsules were collected by using vacuum filtration followed by washing 4-5 times with petroleum ether and dried at room temperature for $24 \mathrm{~h}$.

\subsection{Evaluation of Microcapsules}

2.6.1. Microscopic Observation. Particle size and shape of microcapsules were observed using compound microscope.

2.6.2. Yield of Microcapsules. The prepared microcapsules were collected and weighed. Yield of microcapsules was calculated by actual weight of microcapsules divided by total weight of copolymers and drug:

Percentage yield $=($ Actual weight of microcapsules $/$ Total weight of copolymers and drug) $\times 100$.

2.6.3. Scanning Electron Microscopy. Microcapsules were pragmatic under scanning electron microscope (JEOL 5400, Tokyo, Japan) for surface characteristics and examine the morphology of fracture surface. The sample was dried and coated with a gold ion for 5 to 6 min to obtain $15 \mathrm{KV}$ using $\mathrm{SE}^{2}$ detector at various magnifications [9].

2.6.4. Micromeritic Properties. Flow properties of the microcapsules were evaluated by determining the angle of repose and the compressibility index. Angle of repose was calculated by fixed funnel method. Bulk density was measured by using bulk density apparatus and compressibility index was calculated.

2.6.5. Particle Size Analysis. Particle Size analysis was determined using compound microscope with the help of stage micrometer and eye piece micrometer, counting at least 100 microcapsules per batch. Microcapsules were counted at $10 \mathrm{x}$ magnification.
2.6.6. Percentage Drug Entrapment Efficiency. Accurately weighed microcapsules equivalent to $10 \mathrm{mg}$ of drug were stirred with $100 \mathrm{~mL}$ of $\mathrm{pH} 6.8$ buffer for 2 hours. This solution was filtered and after suitable dilution drug content was estimated spectrophotometrically at $238.5 \mathrm{~nm}$. One has the following:

Percentage drug efficiency $=$ (Amount of drug actually present/theoretical drug load expected) $\times 100$.

2.6.7. Determination of Coating Polymer on Microcapsules. About $1 \mathrm{~g}$ of the microcapsules was accurately weighed and washed 3 times with $10 \mathrm{~mL}$ of acetone in order to remove polymer coating. The remaining drug-resinate core was dried at $50^{\circ} \mathrm{C}$ for $12 \mathrm{~h}$ and weighed. The percentage of coating polymer was calculated by the following equation:

Percentage coating polymer $=($ Microcapsules weight Dried complex weight/Microcapsules weight) $\times 100$.

2.6.8. In Vitro Drug Release Study. Microcapsules equivalent to $40 \mathrm{mg}$ of the drug were used for dissolution study. USP type I dissolution test apparatus was used. The dissolution tests were carried out using $870 \mathrm{~mL}$ of $\mathrm{pH} 1.2$ phosphate buffer for first $2 \mathrm{~h}$ and made up to $900 \mathrm{~mL}$ by adjusting the $\mathrm{pH}$ 6.8 phosphate buffer for remaining $6 \mathrm{~h}$, a speed of $50 \mathrm{rpm}$, and temperature $37 \pm 0.5^{\circ} \mathrm{C}$. The amount of dissolved drug was determined using UV spectrophotometric method at $238.5 \mathrm{~nm}$.

2.6.9. Pharmacokinetic Study Design and Protocol. In vivo study design and protocol were approved by institutional ethical committee. Twenty healthy rats of either sex, weighing 200-220 g, were used for the study; test, standard, and control, in each group $(n=6)$ rats, were used. A crossover experimental design with a washout period of 1 month was followed for testing the formulation. Rats were kept for overnight fasting. Only water was permitted until $24 \mathrm{~h}$ following oral administration of formulation. Microcapsules were suspended in $0.1 \%$ Carboxy methyl cellulose solution and sonicated for $5 \mathrm{~min}$ to get uniform dispersion. Rat dose was calculated based on the weight of the rats. Blood samples were collected from retroorbital plexus vein from rat eye. After collecting the "zero" hour blood sample (blank), $1 \mathrm{~mL}$ sample was administered orally using rat feeding tube. About two $\mathrm{mL}$ of blood samples was collected $0.5,1,2,4,6,8$, 12 , and $24 \mathrm{~h}$ at each time interval after administration. The blood samples were centrifuged at $6000 \mathrm{rpm}$ and serum separated was collected into dry test tubes and all the samples were stored under defreeze maintained temperature $-40^{\circ} \mathrm{C}$. 


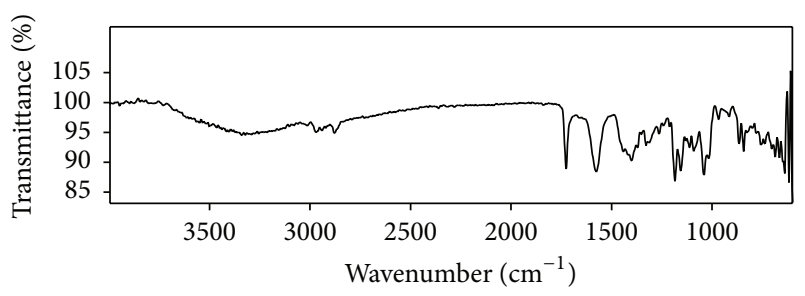

(a)

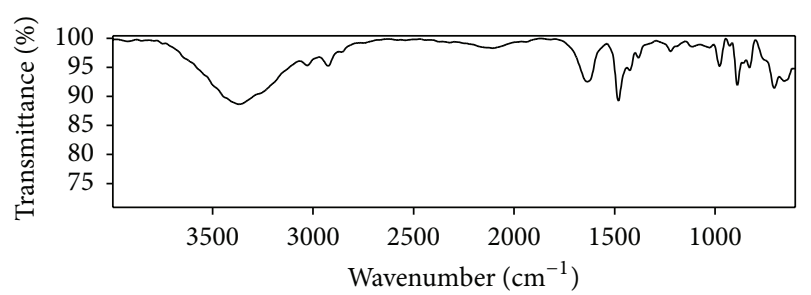

(b)

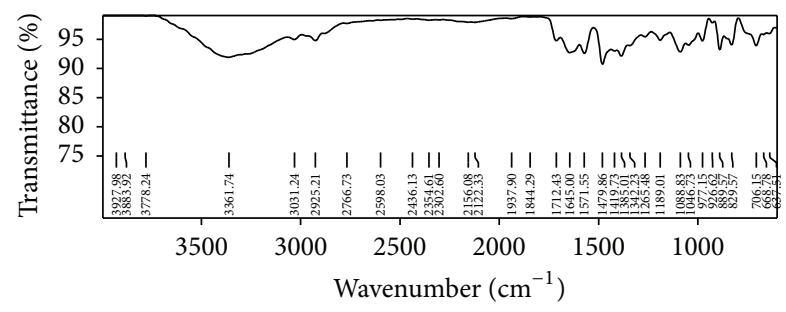

(c)

Figure 1: FTIR Spectra of (a) Pravastatin Sodium, (b) Tulsion 412, and (c) drug-resinates.

Pravastatin Sodium drug from serum concentrations was determined by a HPLC method as follows: methanol $1 \mathrm{~mL}$ was added to $0.5 \mathrm{~mL}$ of serum and agitated for cyclomix for 2 to 3 min followed by using cooling centrifuge at $4^{\circ} \mathrm{C}$ maintained speed $5000 \mathrm{rpm}$ for 10 minutes. The clear liquid was removed and placed in Eppendorf tube. Then the supernatant was diluted with mobile phase Acetonitrile: 1 octane sulphonic acid at $\mathrm{pH}$ 2.5: $60: 40$, flow rate $1 \mathrm{~mL} / \mathrm{min}$, injection volume $20 \mu \mathrm{L}$ of solution injected in to HPLC column (column) dimension ID: $250 \times 4.6 \mathrm{~mm}$, particle size: $5 \mu \mathrm{m}$, and high pressure gradient, detector: UV wavelength: $230 \mathrm{~nm}$.

From the time v/s serum drug concentration data various pharmacokinetic parameters such as peak plasma concentration $\left(C_{\max }\right)$, time at which peak occurred $\left(t_{\max }\right)$, area under the curve, elimination rate constant $\left(K_{\mathrm{el}}\right)$, biological halflife $\left(t_{1 / 2}\right)$, absorption rate constant, and $V_{d}$ were calculated as per known calculation methods. Highest concentration of drug in plasma attained by the administrated dose is $C_{\max }$. Time taken to reach maximum concentration of drug in plasma is $t_{\text {max }}$. Area under the curve was calculated by using trapezoidal rule. $V_{d}$ was calculated by using formula: Administrated dose/Initial plasma drug concentration. Biological half-life was calculated by using formula 0.693/ke [10].

Absorption rate constant was calculated by using method of residuals. Clearance $(\mathrm{Cl})$ was calculated by using formula: Administered dose/AUC. Mean residence time was calculated based on $63.2 \%$ of drug eliminated from the body [7].

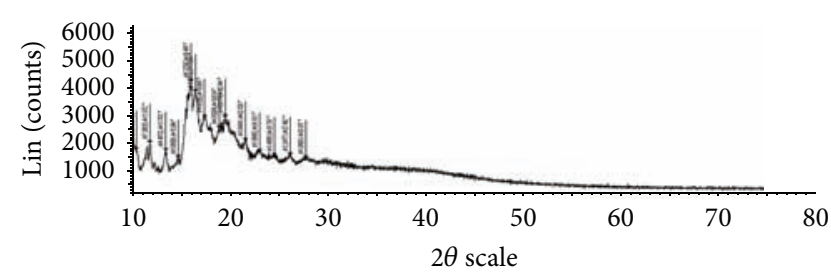

(a)

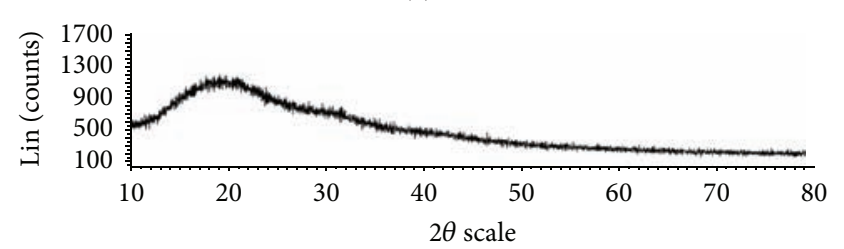

(b)

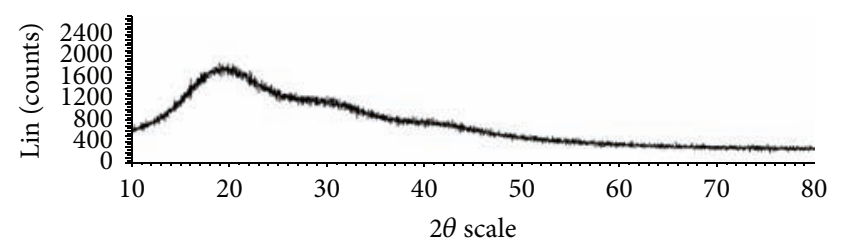

(c)

Figure 2: X-ray diffraction spectra of (a) Pravastatin Sodium, (b) Tulsion 412, and (c) drug-resinates.

2.6.10. Statistical Analysis. Student's paired $t$-test was used for statistical evaluation of the results of two groups. $P$ value of $<0.05$ was considered to represent a statistical significant difference.

2.6.11. Stability Studies. The intermediate stability studies were carried out on the most satisfactory formulations according to ICH guidelines. The formulations were sealed in aluminium packaging and kept in stability chamber maintained at $30 \pm 2^{\circ} \mathrm{C} / 65 \% \mathrm{RH}$ for six months.

\section{Results and Discussion}

Based on the solubility $0.1 \mathrm{~N} \mathrm{HCl}$ and $\mathrm{pH} 6.8$ phosphate buffer was used for constructing the standard graph of Pravastatin Sodium and same medium was used for dissolution studies. Batch method was used for complexation of drug with resins. Maximum drug load was observed in 1:4 ratios. FTIR spectrum of Pravastatin Sodium peaks has $\mathrm{C}=\mathrm{O}$ at $1712 \mathrm{~cm}^{-1}, \mathrm{OH}$ at $3361.74 \mathrm{~cm}^{-1}, 3031 \mathrm{~cm}^{-1}$ due to SP3 $\mathrm{CH}$ stretching, $1479 \mathrm{~cm}^{-1}$ due to $\mathrm{CH}$ bending alkanes, and SP2$\mathrm{CH}$ stretching, which are characteristic peaks of pure drug Pravastatin Sodium; after complexation with resins same considerable peak was observed as shown in the Figure 1. The $\mathrm{X}$-ray diffraction of drug alone shows sharp crystalline peaks after complex with resins most diffused peaks were observed as showed in Figure 2. DSC spectra of pure drug exhibited sharp exothermic peak at $68.9^{\circ} \mathrm{C}$ and $176^{\circ} \mathrm{C}$ and endothermic peak at $257.5^{\circ} \mathrm{C}$. Drug-resinates peaks are deviated due to complexation as shown in Figure 3. The preparation of drugresinate was optimized with respect to drug resin ratio and time of sorption. Drug loading was done by batch 


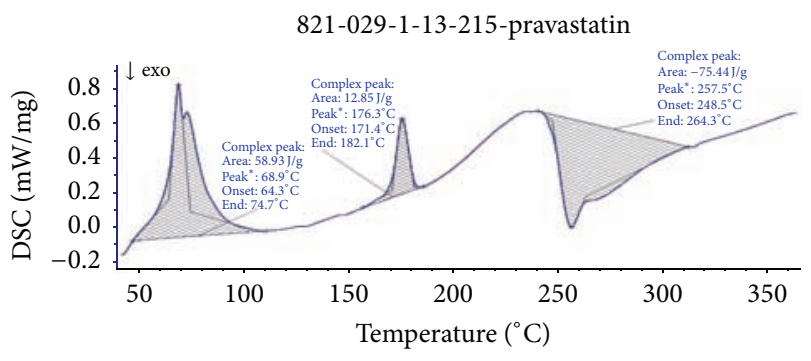

(a)

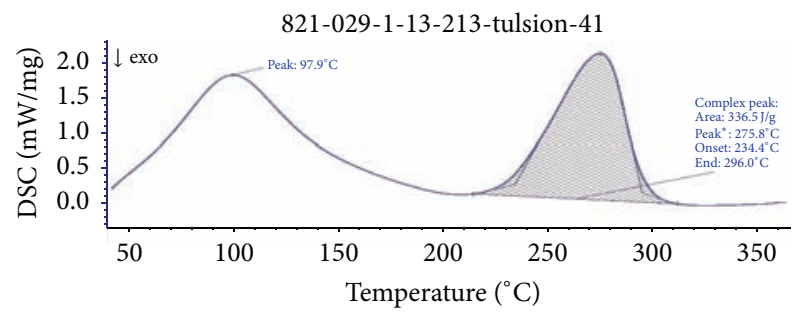

(b)

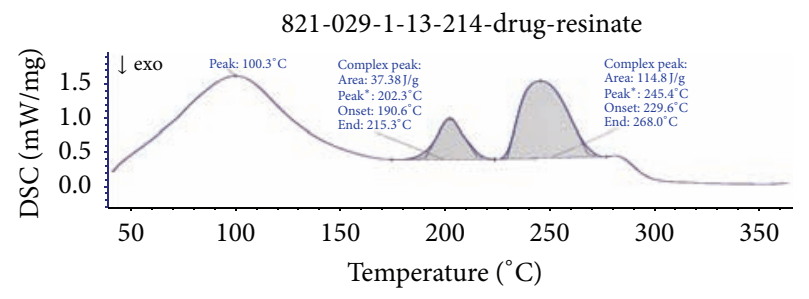

(c)

Figure 3: DSC spectra of (a) Pravastatin Sodium, (b) Tulsion 412, and (c) drug-resinates.

method with cholestyramine anion exchange resin Tulsion 412. It was stirred at $4 \mathrm{~h}$ continuously in which optimum drug load $80.34 \%$ was experimented in 1:4 ratio; even if we increase the drug resin ratios, there was no changes in drug loading. Further batches were prepared by using same 1: 4 ratios. Microcapsules were prepared by nonaqueous solvent evaporation technique. Drug characteristic peaks were observed for prepared microcapsules identified from FTIR spectra of Eudragit RLPO coated microcapsules and RSPO coated microcapsules as shown in Figure 4. Morphology of microcapsules was observed from compound microscope and SEM. Scanning electron micrographs of single and group of Eudragit RLPO and Eudragit RSPO microcapsules were observed. The micro particles were irregular shaped, free flowing powders in case of RLPO microcapsules. Spherical, discrete, and number of microporous surface structure was observed in case of Eudragit RSPO microcapsules as shown in Figure 5. Physicochemical parameters of all f1 to $\mathrm{f} 7$ formulations were showed in Table 2. Microcapsules were free flowing powders. Angle of repose was measured by using fixed funnel method. The angle of repose was observed in the range of $22.0^{\circ}$ to $23.5^{\circ}$; it fulfils the IP requirements. Bulk density was found to be 0.48 to $0.68 \mathrm{~g} / \mathrm{cc}$. The lower values of bulk density were favourable for obtaining higher porosity. Compressibility index was found to be 5.00 to $7.50 \%$. Values

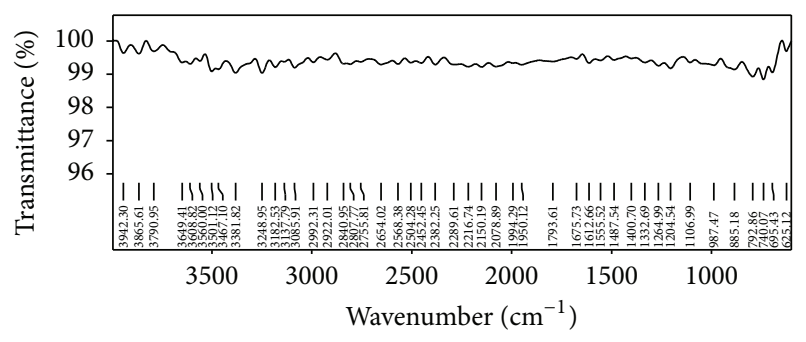

(a)

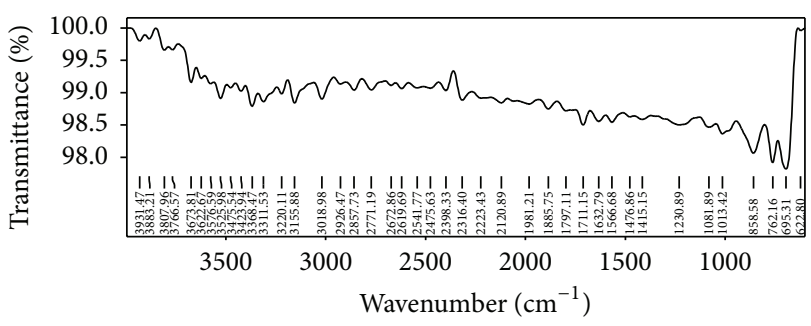

(b)

FIGURE 4: FTIR spectra of Eudragit RLPO coated microcapsules and Eudragit RSPO coated microcapsules.

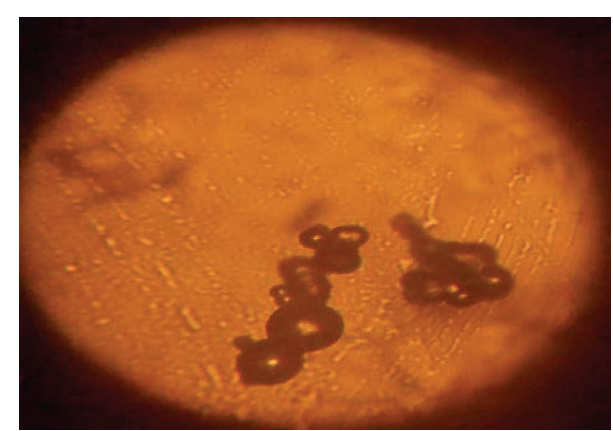

(a)

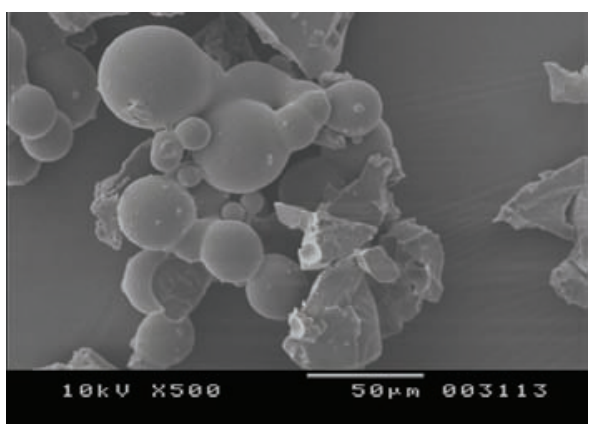

(b)

Figure 5: (a) Microscopic images at 10x magnification and (b) SEM images of Eudragit RSPO microcapsules.

below $15 \%$ usually give rise to good flow and compressibility characteristics. Percentage yield for the batches f1 to $\mathrm{f} 7$ varied from $98.0 \pm 2.2$ to $98.9 \pm 7.5 \%$. Percentage drug entrapment efficiency for the formulations f1 to $\mathrm{f} 7$ varied from $97.0 \pm$ $0.5 \%$ to $98.7 \pm 0.3 \%$. When the polymer coating increases, microcapsules particle size also increases as shown in Table 2. 
TABLE 2: Physicochemical properties of developed formulations.

\begin{tabular}{|c|c|c|c|c|c|c|c|c|}
\hline B-code & $\begin{array}{l}\text { Drug- } \\
\text { resinates to } \\
\text { polymer ratio } \\
(\% \mathrm{w} / \mathrm{w})\end{array}$ & $\%$ yield $^{*}$ & $\begin{array}{l}\text { Angle of } \\
\text { repose }\left({ }^{\circ}\right)^{*}\end{array}$ & $\begin{array}{c}\text { Compressibility } \\
\text { index* }^{*}(\%)\end{array}$ & $\begin{array}{l}\text { Bulk density } \\
\text { (g/cc) }\end{array}$ & $\% \mathrm{DEE}^{*}$ & $\begin{array}{l}\% \text { coating of } \\
\text { polymer }^{*}\end{array}$ & $\begin{array}{l}\text { Particle size } \\
\qquad(\mu \mathrm{m})\end{array}$ \\
\hline f1 & - & $97.0 \pm 2.25$ & 22.0 & 7.15 & 0.56 & $98.9 \pm 0.5$ & $97.4 \pm 0.6$ & $45-198$ \\
\hline $\mathrm{f} 2$ & 10 & $95.1 \pm 3.25$ & 22.2 & 7.50 & 0.48 & $97.1 \pm 0.8$ & $97.6 \pm 2.6$ & 60-199 \\
\hline f3 & 20 & $96.3 \pm 6.30$ & 22.5 & 6.01 & 0.55 & $97.6 \pm 0.8$ & $97.1 \pm 7.8$ & $63-242$ \\
\hline f4 & 30 & $97.9 \pm 7.5$ & 22.3 & 5.61 & 0.40 & $97.9 \pm 0.8$ & $98.7 \pm 8.9$ & $87-323$ \\
\hline f5 & 10 & $98.1 \pm 5.75$ & 22.1 & 5.00 & 0.40 & $97.9 \pm 0.5$ & $97.9 \pm 7.6$ & 59-205 \\
\hline f6 & 20 & $98.8 \pm 7.1$ & 22.5 & 5.55 & 0.41 & $98.7 \pm 0.3$ & $98.6 \pm 8.8$ & $62-214$ \\
\hline f7 & 30 & $97.4 \pm 4.84$ & 22.4 & 6.88 & 0.52 & $98.7 \pm 0.2$ & $98.9 \pm 9.7$ & 80-344 \\
\hline
\end{tabular}

* All the values were average mean of 3 determinations.

TABLE 3: Drug release kinetic data from microcapsules.

\begin{tabular}{lcccc}
\hline Batch & Zero-order $r^{2}$ & First-order $r^{2}$ & Higuchi equation $r^{2}$ & \multicolumn{2}{c}{ Korsmeyer Peppas equation } \\
& & & $r^{2}$ & 0.469 \\
f1 & 0.760 & 0.950 & $\mathbf{0 . 9 7 6}$ & 0.73 \\
f2 & 0.716 & 0.974 & $\mathbf{0 . 9 7 3}$ & 0.462 \\
f3 & 0.760 & 0.922 & $\mathbf{0 . 9 0 1}$ & 0.761 \\
f4 & 0.710 & 0.917 & $\mathbf{0 . 9 7 4}$ & 0.71 \\
f5 & 0.882 & 0.750 & $\mathbf{0 . 9 8 9}$ & 0.761 \\
f6 & 0.911 & 0.736 & $\mathbf{0 . 9 8 1}$ & 0.76 \\
f7 & 0.940 & 0.797 & $\mathbf{0 . 9 7 0}$ & 0.73 \\
\hline
\end{tabular}

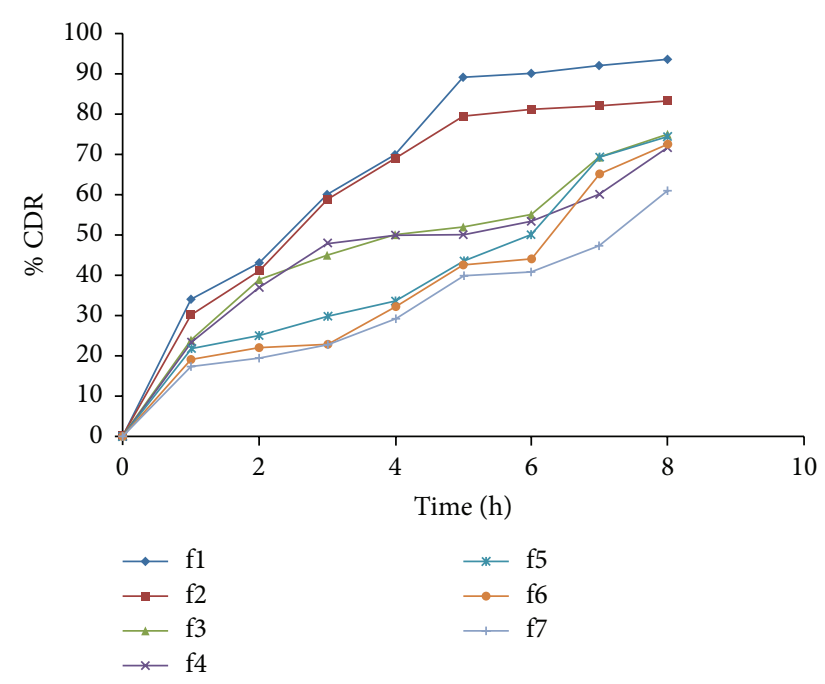

FIGURE 6: In vitro drug dissolution profiles of f1-f7.

The drug release in the acidic media ( $\mathrm{pH} 1.2)$ is low because drug is weak acid and its $\mathrm{pKa}$ value is 4.2 , but, in presence of alkali media $(\mathrm{pH}$ 6.8), drug discharge rate was faster due to phosphate ions. The drug release from the Eudragit RLPO and Eudragit RSPO coated microcapsules shows slower drug release than uncoated resinates. Most satisfactory formulation $\mathrm{f} 6$ showed drug release up to $72.6 \%$ as shown in Figure 6. The drug release data were fitted into drug release kinetic models. It follows mixed order kinetics. Formulations $\mathrm{f} 2$ to $\mathrm{f} 4$ follow first-order kinetics and $\mathrm{f} 5$ to $\mathrm{f} 7$ follow zero-order kinetics observed based on the regression coefficient values as shown in Table 3. The uncoated resinates followed particle diffusion process. However coated resinate deviated from particle diffusion. Microcapsules follow membrane diffusion control mechanism in the drug release system. The data was fitted into KorsmeyerPeppas equation. Based on the $n$ values from 0.56 to 0.76 , this indicates non-Fickian diffusion type of mechanism. The drug release data from Higuchi equation showed comparable linearity. Microcapsules obeyed diffusion controlled process. Based on release kinetics data microcapsules of $\mathrm{f} 5$ and $\mathrm{f} 6$ formulations endowed with a convenient dosage form for achieving controlled release. The $\mathrm{f} 5$ and $\mathrm{f} 6$ drug release data was expressed \pm SD. Paired $t$-test was used for statistical evaluation of results. There were 8 samples for both the groups. $P$ value $<0.05$ was considered to represent a statistical significant difference. Results from dissolution data $\mathrm{f} 5$ and $\mathrm{f} 6$ were statistically significant for $5 \%$ level.

From HPLC method standard calibration data was prepared as shown in Table 4. Standard chromatogram of Pravastatin Sodium pure drug at different time intervals was as shown in Figure 7 and linearity was constructed as shown in Figure 8. Highest sharp peak at 6.205 in the chromatogram was observed. Pravastatin Sodium drug peak was observed at 6.280 in rat plasma as shown in Figure 9. Time versus average serum drug concentrations in microcapsules following oral administration in rats in both test and standard data at differ- 
TABLE 4: Calibration data for pravastatin sodium by HPLC.

\begin{tabular}{lcc}
\hline Serial number & $\begin{array}{c}\text { Linearity-pravastatin } \\
\text { sodium concentration } \\
(\mu \mathrm{g} / \mathrm{mL})\end{array}$ & Peak area \\
\hline 1 & 2 & 57163.261 \\
2 & 4 & 121376.268 \\
3 & 6 & 182935.218 \\
4 & 8 & 247918.698 \\
5 & 10 & 303747.489 \\
6 & 12 & 360683.698 \\
\hline
\end{tabular}

TABle 5: Average serum drug concentration in microcapsules following oral administration in rats.

\begin{tabular}{lcc}
\hline Time $(\mathrm{h})$ & $\begin{array}{c}\text { Avg serum drug conc } \\
\text { test }(\mu \mathrm{g} / \mathrm{mL})\end{array}$ & $\begin{array}{c}\text { Avg serum drug conc } \\
\text { Std }(\mu \mathrm{g} / \mathrm{mL})\end{array}$ \\
\hline 0 & 0 & 0 \\
0.5 & $0.011 \pm 0.0004$ & $0.022 \pm 0.003$ \\
1 & $0.030 \pm 0.0002$ & $0.049 \pm 0.006$ \\
2 & $0.069 \pm 0.002$ & $0.07 \pm 0.004$ \\
4 & $0.071 \pm 0.001$ & $0.041 \pm 0.006$ \\
6 & $0.0417 \pm 0.001$ & $0.0213 \pm 0.002$ \\
8 & $0.0236 \pm 0.001$ & $0.0081 \pm 0.001$ \\
12 & $0.0079 \pm 0.003$ & $0.0061 \pm 0.006$ \\
24 & $0.0052 \pm 0.001$ & $0.0043 \pm 0.003$ \\
\hline
\end{tabular}

ent time intervals were shown in Table 5. Time versus average serum drug concentration profiles (Figure 10), from which AUC pharmacokinetic parameters were calculated, were shown in Table 6. From area under the curve, we can calculate the extent of drug absorption after $24 \mathrm{~h} . C_{\max }$ was observed to be $0.072 \mu \mathrm{g} / \mathrm{mL} ; t_{\max }$ was observed to be $4 \mathrm{~h}$. The $K_{\mathrm{el}}$ for Pravastatin Sodium microcapsules was observed to be $0.14 / \mathrm{h}$ and the resultant biological half-life was found to be $4.95 \mathrm{~h}$. The mean residence time was observed at $6.3 \mathrm{~h}$. Ka was found to be $0.57 / \mathrm{h}$. When compared to standard about 2 -fold increase in mean residence time was observed as shown in Table 6. After 6 months of intermediate stability studies there was no significant changes in $\%$ drug entrapment and in vitro drug release studies were observed as shown in Tables 7 and 8.

\section{Summary and Conclusion}

In case of formulation of Pravastatin Sodium microcapsules, Tulsion 412 ion exchange resins were complexed with the drug in different ratios for $4 \mathrm{~h}$. Drug to resin ratio of $1: 4$ gave maximum amount of complexation achieved, $80.34 \%$. Drug, resins, drug-resinates, and polymers interaction studies were carried out using FTIR, XRD, and DSC studies; there was no interaction observed between drug, resin, and polymers. Drug-resinates were further coated with Eudragit RSPO and Eudragit RLPO polymers for achieving control release in the small intestine. Microcapsules were prepared by using nonaqueous solvent evaporation method. Microencapsuled
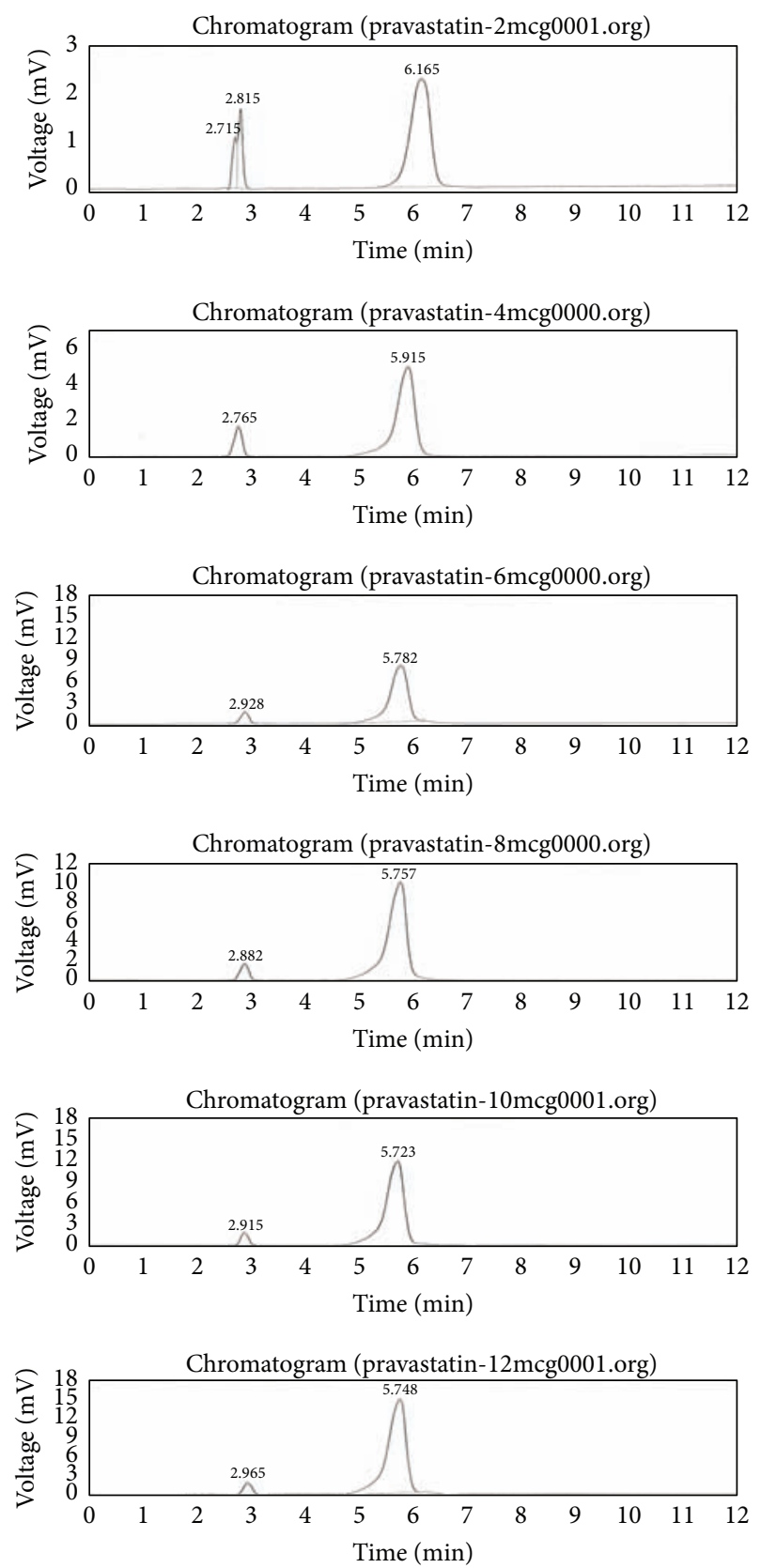

FIGURE 7: Standard calibration chromatogram by using HPLC method.

drug-resinates exhibited satisfactory values of angle of repose and bulk density. The drug content was found to be more than $96 \%$ and then subjected to evaluation studies like percentage yield, surface characteristics, and other physicochemical characteristics. Most satisfactory formulation f6 shows excellent physicochemical characteristics. Better drug retaining characteristics were observed in dissolution process. In vitro dissolution studies showed a drug release up to $75 \%$ in $8 \mathrm{~h}$, which was found to be better drug retaining characteristics. In vivo bioavailability study was conducted by using rats. From pharmacokinetic evaluation, the mean residence time was found to be $6.3 \mathrm{~h}$ and indicates that more 
TABLE 6: Pharmacokinetic parameters.

\begin{tabular}{lcccccccccc}
\hline Product & $C_{\max }$ & $t_{\max }$ & AUC & \% relative BA & $\begin{array}{c}\text { Elimination } \\
\text { rate constant }\end{array}$ & $\begin{array}{c}\text { Biological } \\
\text { half-life }\end{array}$ & Vd & Ka & MRT & Cl \\
\hline Test & $0.072 \mu \mathrm{g} / \mathrm{mL}$ & $4 \mathrm{~h}$ & $0.812 \mu \mathrm{g} / \mathrm{mL}$ & 90.38 & $0.14 / \mathrm{h}$ & $4.95 \mathrm{~h}$ & $16 \mathrm{~L}$ & $0.57 / \mathrm{h}$ & $6.3 \mathrm{~h}$ & $0.293 \mathrm{~h} / \mathrm{mL}$ \\
Std & $0.07 \mu \mathrm{g} / \mathrm{mL}$ & $2 \mathrm{~h}$ & $0.734 \mu \mathrm{g} / \mathrm{mL}$ & - & $0.15 / \mathrm{h}$ & $2.9 \mathrm{~h}$ & $12 \mathrm{~L}$ & $0.50 / \mathrm{h}$ & $3.5 \mathrm{~h}$ & $0.251 \mathrm{~h} / \mathrm{mL}$ \\
\hline
\end{tabular}

TABLE 7: Stability data of most satisfactory f6 formulation.

\begin{tabular}{lccc}
\hline Parameter & Initial & After 3 months & After 6 months \\
\hline Drug entrapment efficiency (\%) & $98.9 \pm 0.1$ & $98.4 \pm 0.2$ & $98.0 \pm 0.1$ \\
\hline
\end{tabular}

TABLE 8: Dissolution data of formulation f6 after stability studies.

\begin{tabular}{|c|c|c|c|}
\hline Time (h) & $\begin{array}{l}\text { Initial } \\
\text { \% CDR }\end{array}$ & $\begin{array}{c}\text { After } 3 \text { months } \\
30 \pm 2^{\circ} \mathrm{C} / 65 \pm 5 \% \mathrm{RH} \\
\% \mathrm{CDR}\end{array}$ & $\begin{array}{c}\text { After } 6 \text { months } \\
30 \pm 2^{\circ} \mathrm{C} / 65 \pm 5 \% \mathrm{RH} \\
\% \mathrm{CDR}\end{array}$ \\
\hline 1 & $24.6 \pm 0.1$ & $23.2 \pm 0.3$ & $22.0 \pm 0.6$ \\
\hline 2 & $39.1 \pm 0.9$ & $38.7 \pm 0.5$ & $38.1 \pm 0.1$ \\
\hline 3 & $45.0 \pm 1.0$ & $43.0 \pm 0.1$ & $42.8 \pm 0.5$ \\
\hline 4 & $50.0 \pm 0.1$ & $49.8 \pm 0.5$ & $49.1 \pm 0.7$ \\
\hline 5 & $51.8 \pm 0.5$ & $50.1 \pm 0.2$ & $49.0 \pm 0.8$ \\
\hline 6 & $54.9 \pm 0.4$ & $54.0 \pm 0.3$ & $53.9 \pm 0.7$ \\
\hline 7 & $69.3 \pm 0.3$ & $68.9 \pm 0.7$ & $68.0 \pm 0.4$ \\
\hline 8 & $75.0 \pm 0.2$ & $74.9 \pm 0.8$ & $74.8 \pm 0.3$ \\
\hline
\end{tabular}

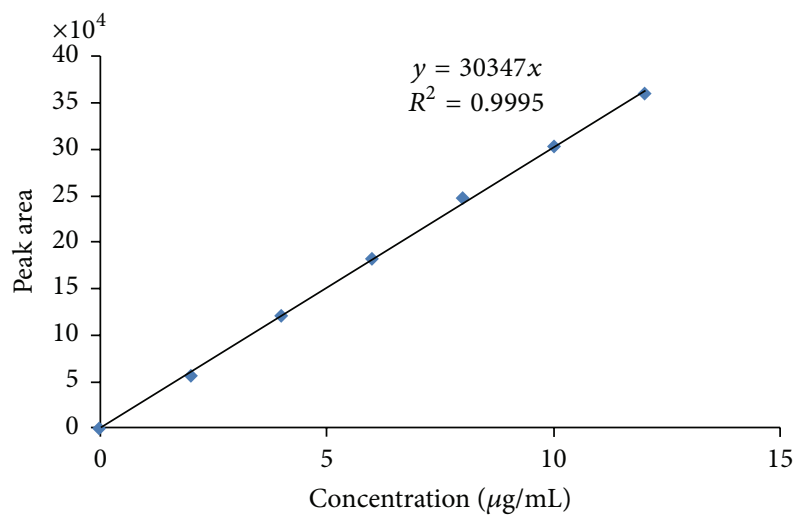

Figure 8: Calibration curve for Pravastatin Sodium by HPLC method.

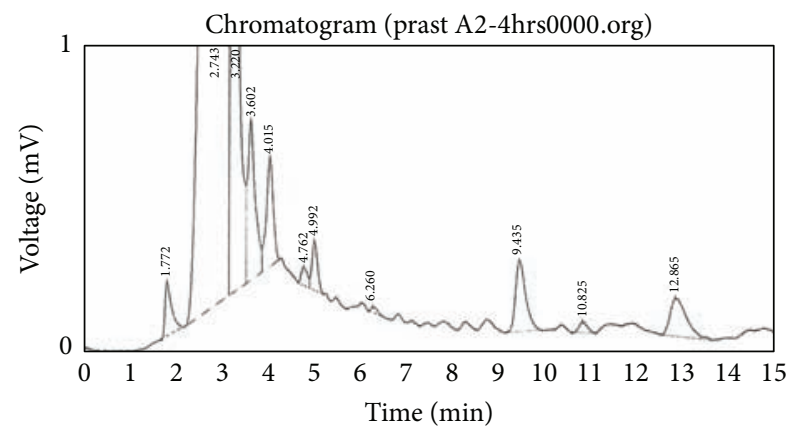

FIGURE 9: Determination of Pravastatin Sodium in rat Plasma by HPLC.

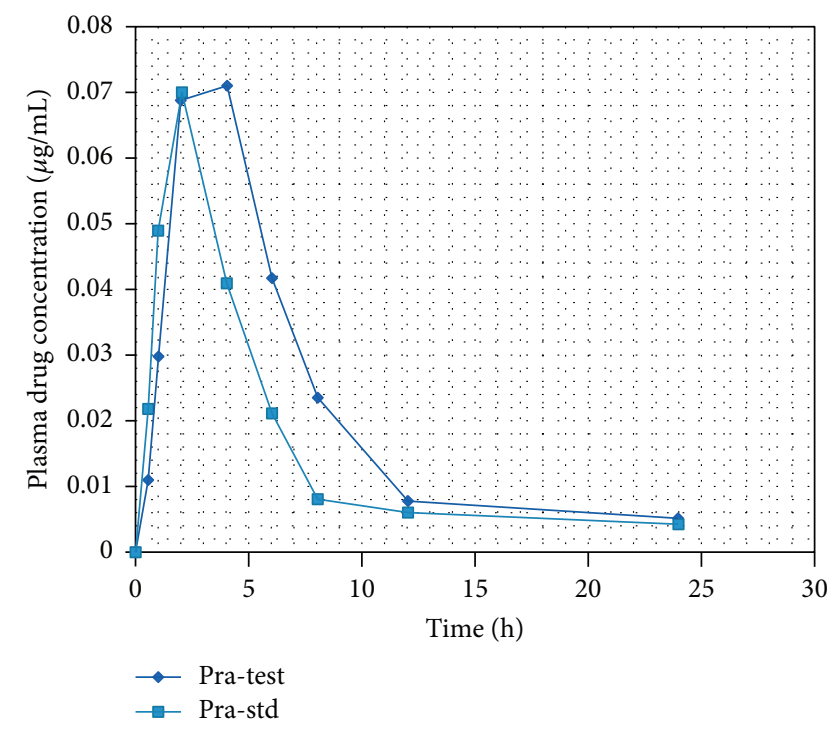

FIgURE 10: Time v/s plasma drug concentration AUC.

residence time was observed, thus indicating that Pravastatin Sodium microcapsules were released and absorbed slowly over a prolonged period of time. Further the formulations were subjected to stability testing for three months. Results revealed no significant changes in the formulations. The results from these studies demonstrated that microencapsules are a viable approach for developing a controlled release solid dosage form of Pravastatin Sodium. Drug-resinates 
coated with Eudragit RSPO (f6) have proved to be efficient carrier for diffusion controlled release microcapsules of Pravastatin Sodium. Optimized formulations provide better drug retaining characteristics; we can decrease the frequency of administration; it also avoids first pass metabolism and dose dumping; we can reduce the dose size and achieve better patient compliance.

\section{Competing Interests}

The authors declare that there are no conflict of interests regarding this paper.

\section{Acknowledgments}

The authors wish to thank JNTU, Hyderabad, for creating opportunities to carry out research work and thanks are due to to Biocon India Pvt Ltd, Bengaluru, and Thermax Ion exchange resins Ltd, Mumbai, for providing gift sample Pravastatin Sodium and Tulsion 412 resin, respectively. They also thank Chairman Mr. Premnath Reddy and Ms. Shalini Reddy for providing research facilities to work in Acharya and B. M. Reddy College of Pharmacy laboratory, Bengaluru.

\section{References}

[1] P. Kathleen, Ed., Martindale: The Complete Drug Reference, The Pharmaceutical Press, London, UK, 32nd edition, 1999.

[2] B2-new-1-Rohm and Haas Company, Rohm and Haas Company, http://www.dow.com/assets/attachments/business/process_ chemicals/amberlite_and_duolite_pharmaceutical_grade_resins/ duolite_ap143-1083/tds/duolite_ap143-1083.pdf.

[3] W. J. R. Irwin, R. Machale, and P. J. Watts, "Drug-delivery by ion-exchnage. Part VII: release of acidic drugs from anionic exchange resinate complexes," Drug Development and Industrial Pharmacy, vol. 16, no. 6, pp. 883-898, 1990.

[4] M. Sriwongjanya and R. Bodmeier, "Effect of ion exchange resins on the drug release from matrix tablets," European Journal of Pharmaceutics and Biopharmaceutics, vol. 46, no. 3, pp. 321327, 1998.

[5] D. Torres, L. Boado, D. Blanco, and J. L. Vila-Jato, "Comparison between aqueous and non-aqueous solvent evaporation methods for microencapsulation of drug-resin complexes," International Journal of Pharmaceutics, vol. 173, no. 1-2, pp. 171$182,1998$.

[6] V. B. Junyaprasert and G. Manwiwattanakul, "Release profile comparison and stability of diltiazem-resin microcapsules in sustained release suspensions," International Journal of Pharmaceutics, vol. 352, no. 1-2, pp. 81-91, 2008.

[7] D. P. Venkatesh, R. Karki, S. K. Jha, L. A. Geetha, K. G. S. Santha, and D. Goli, "Formulation and evaluation of microspheres containing fluvastatin sodium," International Journal of Drug Development and Research, vol. 4, no. 2, pp. 306-314, 2012.

[8] A. U. Kadam, D. M. Sakarkar, and P. S. Kawtikwar, "Development and evaluation of oral controlled release chlorpheniramine-ion exchange resinate suspension," Indian Journal of Pharmaceutical Sciences, vol. 70, no. 4, pp. 531-534, 2008.

[9] M. R. Bhalekar, J. Avari, and R. A. Umalkar, "Preparation and in vitro evaluation of sustained release drug delivery system for
Verapamil HCL," Indian Journal of Pharmaceutical Sciences, vol. 69, no. 3, pp. 418-422, 2007.

[10] P. L. Madhan, Biopharmaceutics and Pharmacokinetics, Jaypee Brothers, New Delhi, India, 2nd edition, 2000. 

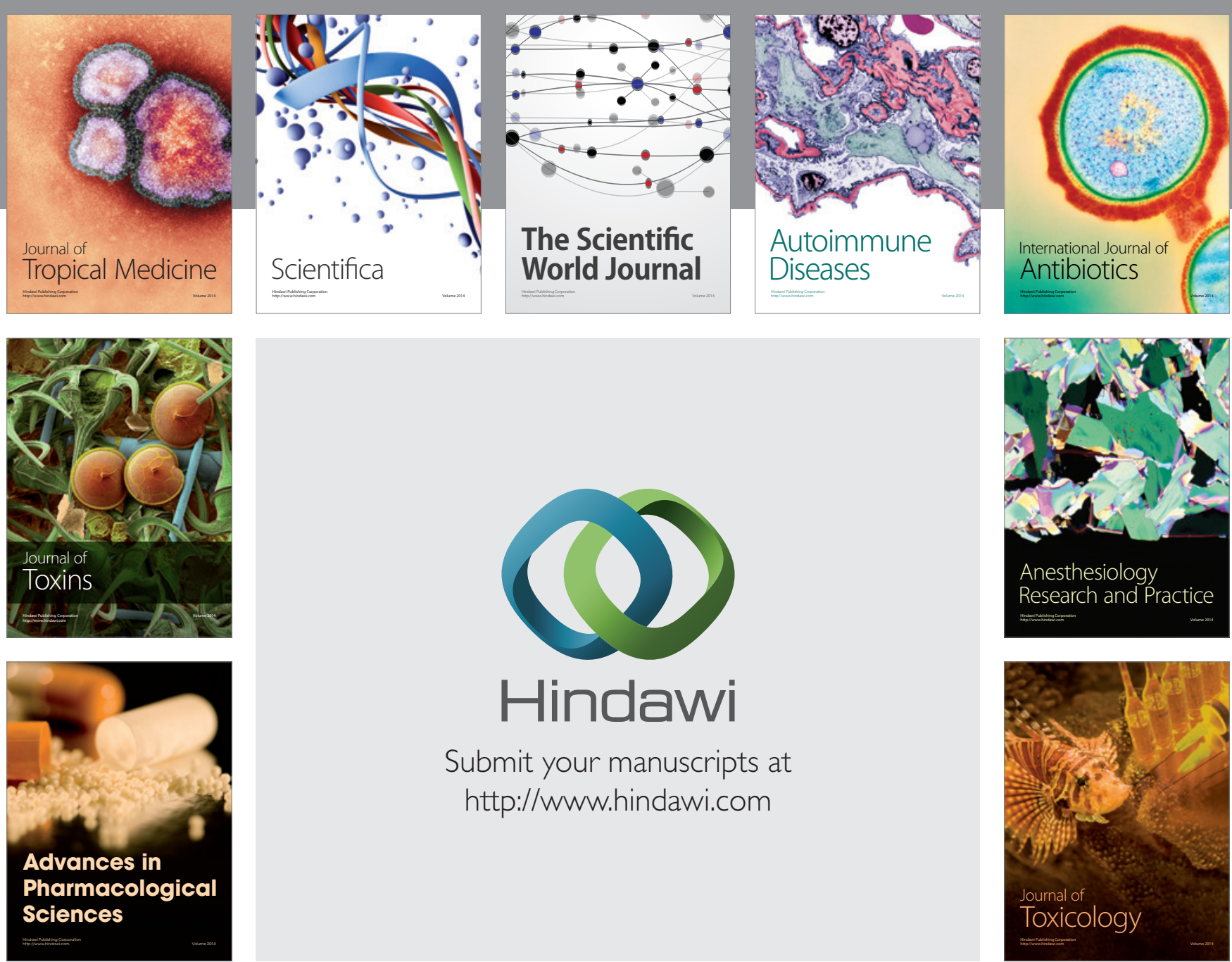

\section{Hindawi}

Submit your manuscripts at

http://www.hindawi.com
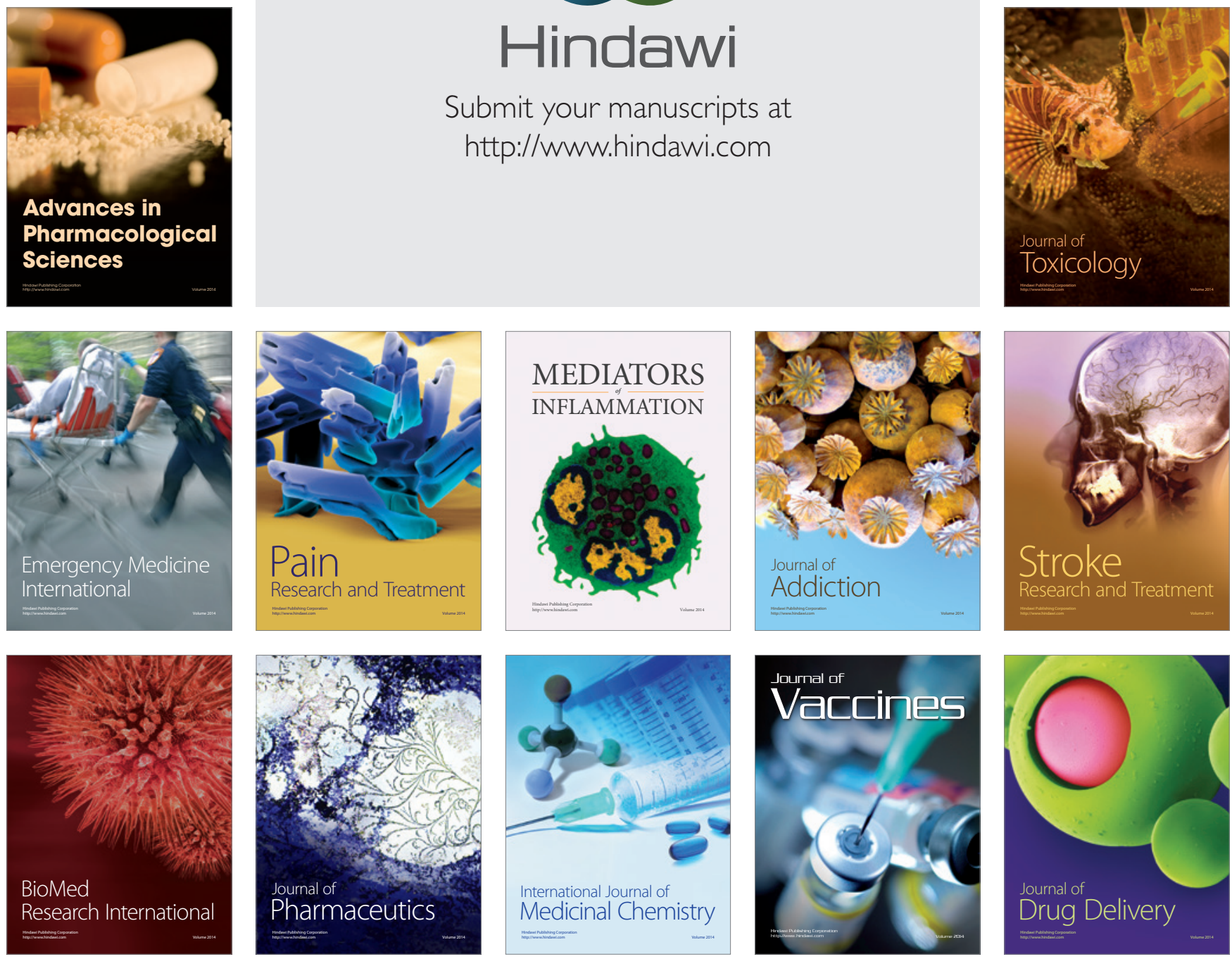